\title{
Antibiotic Resistance: An Investigation on Effectiveness of Antibiotics Treatment on Bacterial Growth
}

\author{
Okoro Monday Akinyemi \\ Department of Science and Social Sciences, Peterborough Regional College, Peterborough, United Kingdom \\ Email: Okoro.akinyemi@hotmail.co.uk
}

How to cite this paper: Akinyemi, O.M. (2020) Antibiotic Resistance: An Investigation on Effectiveness of Antibiotics Treatment on Bacterial Growth. Open Access Library Journal, 7: e6347.

https://doi.org/10.4236/oalib.1106347

Received: April 23, 2020

Accepted: May 19, 2020

Published: May 22, 2020

Copyright $\odot 2020$ by author(s) and Open Access Library Inc.

This work is licensed under the Creative Commons Attribution International License (CC BY 4.0).

http://creativecommons.org/licenses/by/4.0/

(c) (i) Open Access

\begin{abstract}
Background: The proclivity of bacteria resistance to antibiotics has led researchers to develop more interest in antibiotics efficiency in tackling bacterial infections. As part of the effort to finding final resolutions to antibiotics effectiveness, this study was conducted to ascertain the antibiotic sensitivity pattern of three bacterial strains, this study was carried out from March 2019 to June 2019, using different antibiotics such as Ampicillin (AMP), Tetracycline (TET), Erythromycin (ERY), Chloramphenicol (C) Cephalexin (CN), Doxycycline (DO) and Streptomycin (STR) on E. coli, Staphylococcus albus and Bacillus megaterium as part of a project. The potential antagonistic effects were observed in all the antibiotics but with different effects on bacteria strains. Some of the antibiotics were very effective in some bacterial strains and others were less effective. The results obtained evidence that tetracycline has more effects on E. coli and Bacillus meg, but less effective on Staphylococcus. The most effective antibiotic for $E$. coli was chloramphenicol while the least effective was erythromycin. For Staphylococcus albus, the investigation result found Cephalexin to be more effective, while the least effective was ampicillin. However, Doxycycline also appeared to be more effective on Bacillus megaterium compared to chloramphenicol.
\end{abstract}

\section{Subject Areas}

Science and Medicine, Biomedical, Diseases Treatment

\section{Keywords}

Antibiotic, Resistance, Infection \& Treatment, Erythromycin, Cephalexin, Chloramphenicol 


\section{Introduction}

Antibiotic has been the key to improving performance and tackling antimicrobial resistance in both human and other animals for many years. With the evolution of improved methods of disinfection and surgical asepsis, minimally traumatic surgical techniques and the use of antibiotics to prevent infection, the incidence of postoperative endophthalmitis rapidly decreased from $10 \%$ during the late 1800 s to substantially less than $1 \%$ in the modern surgical era (Axenfeld, 1908) [1]. The advent of multidrug resistance among pathogenic bacteria is imperilling the worth of antibiotics, which have previously transformed medical sciences. The crisis of antimicrobial resistance has been ascribed to the misuse of these agents and due to unavailability of newer drugs attributable to exigent regulatory requirements and reduced financial inducements (Aslam et al., 2018) [2]. Evidence has shown the beneficial effects of antibiotics used in many studies, however, despite their effectiveness, the issue of over prescription has dominated the media and in the medical field. According to Jun et al. (2017) [3], the efficacy of antimicrobials is influenced by many factors: 1 ) bacterial status (susceptibility and resistance, tolerance, persistence, biofilm) and inoculum size; 2) antimicrobial concentrations; 3 ) host factors (serum effect and impact on gut micro-biota). The commonly used antimicrobials to treat bacterial infections have both safety and side effects, but they are generally safe and tolerated in the short-term (Suleyman and Zervos, 2016) [4]. However, serious long-term adverse effects may occur, it is therefore crucial for antibiotic selection to be individualised based on source of infection. There should be implementation standard precautions and infections control measures, minimising unnecessary antibiotic exposure, and optimising treatment and duration with removal of source of infection are all essential mechanisms to prevent the widespread resistance and improved outcomes (Suleyman and Zervos, 2016) [4].

According to Dr. Bearison of American Society for Microbiology, researchers at the USDA-ARS have investigated the consequences of antibiotic exposure on Salmonella, including multidrug-resistant strains for many years. They posited that while antibiotics are important drugs to preventing and curing diseases in humans and animals, the drugs can also have unintentional side effects if not properly administered for use.

Also, evidence from various researchers have shown that additional understanding of the linkage between antimicrobial usages, bacterial status and host response will offer researchers a new insight into how microbes can be combated and promote the struggle for the design of antimicrobial treatment prescription that would reach better clinical outcomes (Jun et al., 2017) [3].

The use of antibiotics will inevitably eradicate bacterial infections in human and in some animals when administered correctly. Antibiotics serve as growth promoter additives in animal feed (Nathan and Cars, 2014) [5]. Many antibiotics can be excreted via urine and faeces as unchanged and active species (Rosi-Marshall and Kelly, 2015) [6]. Antibiotics are natural, synthetic and semi-synthetic com- 
pounds that show antimicrobial activities (Catteau et al., 2018) [7]. Antibiotics are currently the most successful family of drugs used in treating microbial infections in humans and animals, with specific action on the target (Kumar et al., 2019) [8]. The use of antibiotics in modern medicine has played a significant role in decreasing the spread of diseases, however, over prescription of the drug in the recent years has caused most strains to become resistance to treatment. An accelerated use of known antimicrobials for human, animals, and agriculture benefit revealed that regular and repeated use of antibiotics have negative implication to the environment and natural ecosystem (Nielsen et al., 2018) [9]. Antimicrobial resistance (AMR) poses a serious global threat of growing concern to human, animal, and environment health. This is due to the emergence, spread, and persistence of multidrug-resistant (MDR) bacteria or "superbugs" (Davies and Davies, 2010) [10].

Antibiotics do not only affect the target population in which it was meant to treat, but also influence the non-target population with high toxicity impact (Grenni et al., 2018) [11]. In many instances, antibiotic residues in the environment can influence the selection of microorganisms and promote the dissemination of antibiotic resistant bacteria and antibiotic resistance genes (Rizzo et al., 2013) [12]. According to Berendonk et al., (2015) [13], Zhou et al., (2013) [14] and Seiler and Berendonk (2012) [15], heavy metals can pose a co-selection pressure for antibiotic resistance, which ultimately lead to the emergence of multiple resistance strains for heavy metals and antibiotics.

\section{The Aim of the Experimental Trial}

This study aimed to investigate and identify the resistance of Staphylococcus albus, Bacillium megaterium and E. coli to tetracycline, doxycycline, ampicillin, chloramphenicol, cephalexin, streptomycin and Erythromycin.

\section{Material and Methods}

The beginning of the trial started with risk assessment to ensure hazard control mechanism was in place. To avoid cross contamination of equipment, Bunsen burner and ethanol were used to disinfect the equipment.

During the trial, agar plates were prepared 24 hours prior to culturing the bacteria. 12 plates were labelled with each bacteria, date and time of the inoculation. The bacterial growth assays were inoculated into nutrient broth in agar plate and were left for 30 minutes to allow the bacteria to adapt and settle on the plates. Thereafter, the plates were stamped using Bio-Rad disks of $6.5 \mathrm{~mm}$ disks made from superior quality absorbent paper and impregnated with precise concentrations of antimicrobial agents' samples such as ampicillin (AMP), tetracycline (TET), erythromycin (ERY), chloramphenicol (C) cephalexin (CN), streptomycin (STR) and Doxycycline (DO). These were incubated at $25^{\circ} \mathrm{C}$ for seven days. This same process was repeated three times during 8 weeks period. After each trial, work area and equipment were disinfected with virkon to eradicate 
any bacteria residue in order to create a safer place for others using the lab for experiment or investigation.

During each trial, the zone of inhibition was calculated; using $A=\pi r^{2}$ and the results were recorded. Data were presented as mean and standard deviation as a cumulative trial. The data was manually calculated to determine statistical significance at $\mathrm{p}<0.05$. The closer the value is to 0.00 , the better, showing minimum significance difference between the mean of each bacterium. The values showing higher numbers specify that there is a significance difference between the values used to produce the mean and the mean itself.

For an effective documentation of the result accuracy, reliability and validity in this trial, the time was organised to allow proper check of the bacteria growth and data collation. A contingency plan was put in place in case there is any short of equipment and materials required to carry out the trial.

\section{Experimental Data Design}

Several indicators were used to measure antibiotic use in each trial. The most commonly used metric was the design of the dosage put in the plate. The investigator ensures the dosage in each trial was equal as a control measure to avoid overdose that may influence the results. However, there were several limitations on the uses as occasionally, the antibiotics disks developed a problem that could not be resolved the same day, but an alternative was used to ensure the timescale was met. It is though believed that specific combinations of drugs would reduce drug resistant bacterial infections. As presented in Table 1, the sample treatments with the antibiotics have different inhibition zones. Negative results were achieved in some of the trials; probably due to the bacteria being resistance to treatment or due to contaminated equipment, systematic or sample errors. However, the repeated experiment ensures the minimization of any error during the trial.

During the first trial, E. coli was treated with seven different antibiotics, however, erythromycin shows very low inhibition zone. Data suggests the potential inhibitory effect of ampicillin, tetracycline, chloramphenicol, cephalexin, and doxycycline on the bacterial infections.

The result shows that different antibiotics have different inoculum effects on the growth and selection of resistance of the same strain. However, a small inoculum effect was observed for some of the antibiotic like erythromycin and a significant inoculum effect for chloramphenicol on $E$. coli. The researcher sees the need to put recommendation forward on the future research of the effectiveness of chloramphenicol use for $E$. coli due to its effectiveness in this trial.

The trial result (Figure 1) reveals chloramphenicol, a promising drug that can reduce the rate of $E$. coli spread and resistance to treatment. Many antibiotic resistances have become a major global public health problem (Aslam et al., 2018) [2]. Therefore, chloramphenicol is of unique interest for a variety of reasons (Hahn, 1967) [16]. It is the first antibiotic to be completely synthesised by methods of organic chemistry and is still the only antibiotic that is industrially produced by chemical synthesis rather than by fermentation (Hahn, 1967) [16]. 
Table 1. Mean of inhibition zone of different treatments of bacterial species.

\begin{tabular}{|c|c|c|c|c|c|}
\hline \multicolumn{6}{|c|}{ Inhibition zone of Bacteria strains } \\
\hline Antibiotics & Bacteria strains & $1^{\text {st }}$ trial & $2^{\text {nd }}$ trial & $3^{\text {rd }}$ trial & Mean average \\
\hline \multirow{3}{*}{ STR } & E. coli & 2.01 & 1.53 & 1.13 & 1.56 \\
\hline & Bacillus megaterium & 2.54 & 2.01 & 2.01 & 2.19 \\
\hline & Staphylococcus albus & 2.01 & 1.13 & 1.54 & 1.56 \\
\hline \multirow{3}{*}{ AMP } & E. coli & 2.83 & 0.5 & 1.13 & 1.49 \\
\hline & Bacillus megaterium & 3.8 & 2.54 & 0 & 3.17 \\
\hline & Staphylococcus albus & 1.54 & 0.79 & 0 & 1.16 \\
\hline \multirow{3}{*}{ TET } & E. coli & 2.01 & 0 & 0 & 2.01 \\
\hline & Bacillus megaterium & 3.14 & 0 & 0 & 3.14 \\
\hline & Staphylococcus albus & 0 & 0 & 0 & 0 \\
\hline \multirow{3}{*}{ ERY } & E. coli & 1.33 & 0 & 0.5 & 0.91 \\
\hline & Bacillus megaterium & 2.54 & 2.54 & 0 & 2.54 \\
\hline & Staphylococcus albus & 2.01 & 2.01 & 2.01 & 2.01 \\
\hline \multirow{3}{*}{$\mathrm{C}$} & E. coli & 3.8 & 2.01 & 1.54 & 2.45 \\
\hline & Bacillus megaterium & 2.01 & 1.53 & 2.01 & 1.85 \\
\hline & Staphylococcus albus & 2.01 & 2.01 & 2.01 & 2.01 \\
\hline \multirow{3}{*}{$\mathrm{CN}$} & E. coli & 3.14 & 0.79 & 0.79 & 1.57 \\
\hline & Bacillus megaterium & 2.54 & 2.01 & 2.54 & 2.36 \\
\hline & Staphylococcus albus & 3.14 & 2.54 & 3.14 & 2.94 \\
\hline \multirow{3}{*}{ DO } & E. coli & 0 & 0 & 1.54 & 1.54 \\
\hline & Bacillus megaterium & 0 & 4.52 & 3.8 & 4.16 \\
\hline & Staphylococcus albus & 0 & 2.01 & 0.5 & 1.25 \\
\hline
\end{tabular}

Trends in mean of the effects of different antibiotics such as ampicillin (AMP), tetracycline (TET), streptomycin (STR) erythromycin (ERY), chloramphenicol (C) cephalexin (CN) and doxycycline (O) on E. coli.

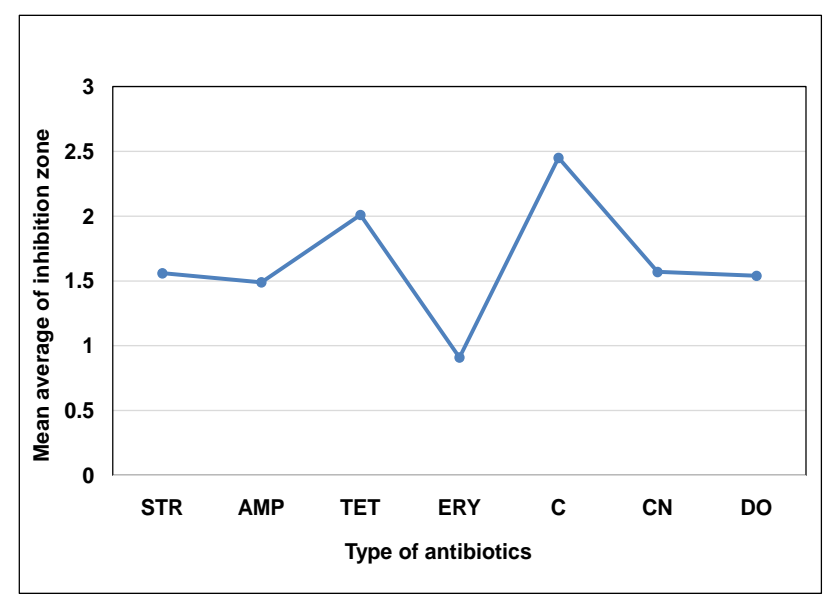

Figure 1. Effects of antibiotics on E. coli (Zone of inhibition $\left(\mathrm{cm}^{2}\right)$. Trends in mean of the effects of different antibiotics such as ampicillin (AMP), tetracycline (TET), streptomycin (STR) erythromycin (ERY), chloramphenicol (C) cephalexin (CN) and doxycycline (O) on E. coli. 
Several authors such as Brock (1961) [17], Davis and Feingold (1962) [18], Gale (1963) [19], Hahn (1964) [20], Goldberg (1965) [21] and Vazquez (1966) [22] have provided evidence on advancement in knowledge of the mechanism of action for chloramphenicol. Chloramphenicol is a widely used antibiotic with nitro and chlorine substituents which is resistant to traditional biological treatments (Nie et al., 2014 [23] and Pilehvar et al., 2012) [24]. Bio-electrochemical system is an efficient method for Chloramphenicol wastewater treatment because it removes the chlorine substituent and transforms the nitro group into amino substituent (Liang et al., 2013 [25]; Yan et al., 2019 [26], Guo et al., 2017 [27]; Sun et al., 2013 [28]; Yan et al., 2018 [29] and Wang et al., 2011) [30].

It is therefore absolutely vital to exploit more benefit of chloramphenicol's effectiveness treatment of E. coli. Potrykus and Wegrzyn (2011) [31], once state that an E. coli strain (strain CM2555) bearing the chloramphenicol acetyltransferase ( cat) gene was found to be sensitive to chloramphenicol, when it was tested on cat gene. According to Brock, (1961) [17], chloramphenicol has been known to inhibit the growth of bacteria, and its mode of action is thought to be by inhibition of protein synthesis. Lacks and Gros (1960) [32] also found that the initial rate of incorporation of radioactive amino acids into RNA in E. coli treated with chloramphenicol was decreased by $80 \%$.

Previous research also shows that a strain of $E$. coli is partially resistant to tetracycline (Franklin and Godfrey, 1965) [33]. However, this trial disproof this idea as the rate of treatment throughout the trial period was consistent. Tetracycline antibiotics are well known for their broad spectrum of activity, spanning a wide range of Gram-positive and -negative bacteria, spirochetes, obligate intracellular bacteria, as well as protozoan parasites. The first tetracyclines were natural products derived from the fermentations of actinomycetes (Grossman, 2019) [34]. When tetracycline was discovered in 1950s, their antimicrobial spectrum was broader than any other antibiotic known then (Dürckheimer, 1975) [35]. Tetracyclines are characterised by their exceptional chemotherapeutic efficacy against a wide range of Gram positive and Gram-negative bacteria (Dürcheimer, 1975) [35]. The main use of tetracycline is due to its effectiveness in infectious diseases caused by E. coli and Haemophilus influenzae. Tetracycline are inexpensive antibiotics which cannot be used to treat human but has been used extensively in the prevention and therapy of animal infections and at subtherapeutic levels in animal feed as growth promoters (Chopra and Robert 2001) [36]. Tetracycline prevents aminoacyl-tRNA to the ribosomal acceptor site (Chopra and Robert 2001) [36]. It plays an important role against a wide range of gram-positive and gram-negative bacteria in tropical organisms.

Bacillus megaterium can be infection to human; it is thought that understanding the antibiotic spectrum of these pathogens and their common mechanisms of antibiotic resistance is crucial. It is therefore crucial to understand the mechanisms associated with the emergence and distribution of the resistance of this infectious disease. Antibiotics which appear especially useful in the treatment of 
Bacillus infections are clindamycin and vancomycin, to which clear majority of the strains are susceptible in vitro. Beta-lactam antibiotics, including the new cephalosporins and penicillin, are of little value in this setting (Sliman, R., Rehm, S. and Shlaes, D.M. 1987) [37].

This trial discloses positive use of doxycycline antibiotic on Bacillus megaterium bacteria. During the trial, it was observed that the zone of inhibition of doxycycline outweighed that of ampicillin, tetracycline, erythromycin, chloramphenicol, streptomycin and cephalexin. Ampicillin also had a significant effect on the bacteria and the least effective antibiotic was cephalexin. It is essential to note that some difficulties were encountered during the documentation of this data. The concerns were centred on data recorded for ampicillin. Two sets of results were recorded for the different trials. Some had a higher inhibition zone average, and others were either very low or zero which created doubt whether there were some anomalies in the data. The three repeated trials were used to avoid significant error that may have occurred.

The treatment of Bacillus megaterium using different antibiotics also produced different results based on the effectiveness of the antibiotics. Members of the Bacillus genus are generally found in soil and most of these bacteria have the ability to disintegrate proteins, namely proteolytic activity. It was reported that the resistance to cephalexin was due to how Bacillus synthesised cephalexin. An examination of the antibiotic resistance of the bacteria strains revealed the Bacillus megaterium was highly resistance to streptomycin and cephalexin.

According to Aslim et al. (2002) [38], Bacillus megaterium strains have an antagonistic effect on antibiotics. Bacillus megaterium strain can be used in certain biotechnological studies. Staphylococcus albus was also tested on the antibiotic ampicillin, tetracycline, erythromycin, chloramphenicol, cephalexin, streptomycin and doxycycline.

The results obtained from the use of streptomycin produced three values which were different; however, there was no significant difference between them (Figure 2). They were all in the range of 1 to $2 \mathrm{~cm}^{2}$ and were valuable results when compared to the rest of the data. Ampicillin also shows two sets of results with numbers different from each other. Erythromycin unveils much accurate result with all recorded data closed to each other. Chloramphenicol data obtained during the trials suggest reliability and accuracy of the data.

In relation to the effectiveness of preventing Staphylococcus growth, cephalexin presents a more promising outcome. Three trials were carried out and two of the results manifest positive correlation. As for, doxycycline, the numbers were assumed not to be accurate as expected, due to significant difference between the inhibition zone in the different weeks. However, when ampicillin was compared with doxycycline, there was no significant difference. The average result for both had little effects on Staphylococcus growth. There was a large significant difference between cephalexin and erythromycin, despite both having significant effects on the treatment Staphylococcus albus. 


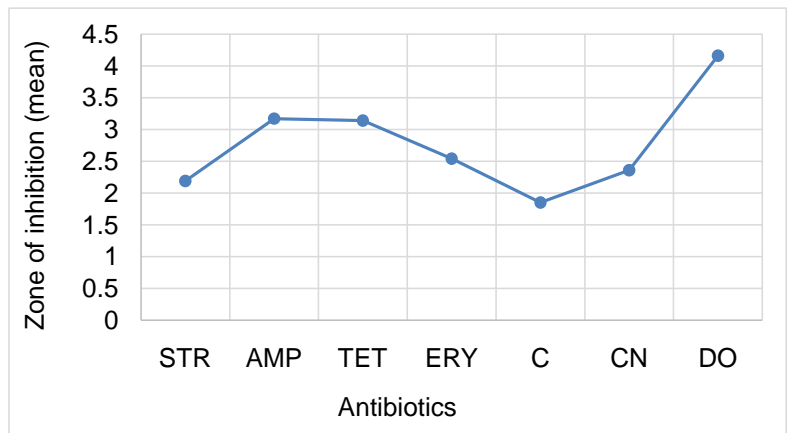

Figure 2. Bacillus megaterium bacteria (Zone of inhibition $\left(\mathrm{cm}^{2}\right)$. Trends in mean of the effects of different antibiotics such as ampicillin (AMP), tetracycline (TET), erythromycin (ERY), chloramphenicol (C) cephalexin (CN), streptomycin (STR) and doxycycline (O) on Bacillus megaterium.

When compared the mean of the different bacteria strains with the antibiotics used, doxycycline had the highest mean value followed by ampicillin and tetracycline respectively. However, no result was obtained from tetracycline on staphylococcus treatment. The comparison of the data shows a clear correlation which tallied with the idea of Lee et al. (2010) [39] investigation. Antibiotic-associated signal can influence the resistance development in bacterial population (Lee et al., 2010) [39]. Under an increasing concentration of norfloxacin, highly resistant $E$. coli population excreted indole as a signalling molecule to the susceptible population, which can cause susceptible strains to regulate the efflux pump expression (Lee et al., 2010) [39]. However, there is no evidence that antibiotic can function as a signal, but can lead to the selection of bacteria that would produce signal, which, in turn, increased the MIC of the entire population (Andersson and Hughes, 2014) [40].

In this investigation, cephalexin was found to be an effective treatment for Staphylococcus albus (Figure 3). The study carried out by Rayner and Munckof (2006) [41] revealed that Staphylococcal infections are a common and significant clinical problem in medical practice. Most strains of Staphylococcus albus are now resistant to penicillin, and methicillin-resistant strains of $S$. albus (MRSA) are common in hospitals and are emerging in the community. This investigation result agrees with report of Rayner and Munckof. New antibiotics such as linezolid and quinupristin or dalfopristin have been revealed to have a good anti-staphylococcal activity. However, the cost to purchase the drug is expensive (Rayner and Munckof, 2006) [41]. The resistance of staphylococcus to tetracycline in the trial unveils a greater value than all the antibiotics used. Compared to erythromycin, there was a significant difference $2.94>2.27$ which disclosed that patients will respond faster to tetracycline than erythromycin.

This research study evidence indicates that $E$. Coli manifest resistant to erythromycin due to the inhibition zone lower than $1 \mathrm{~cm}^{2}$, while Staphylococcus albus and Bacillus megaterium have larger zone of inhibition (Figure 4). A general analysis of this data table disclosed that doxycycline, ampicillin and tetracycline 


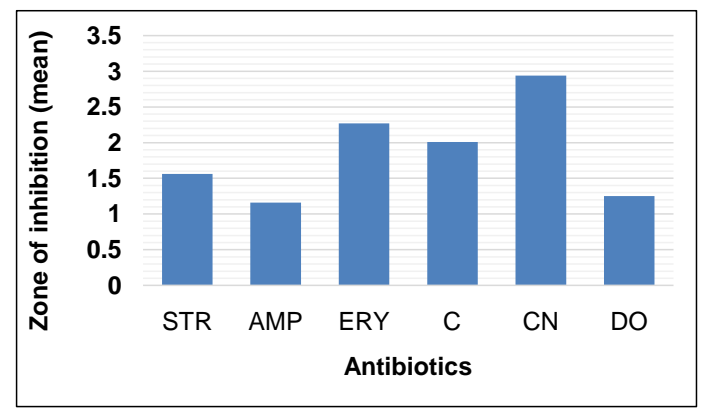

Figure 3. Staphylococcus albus (zone of inhibition $\left(\mathrm{cm}^{2}\right)$. Trends in mean of the effects of different antibiotics such as ampicillin (AMP), tetracycline (TET), erythromycin (ERY), chloramphenicol (C) cephalexin (CN), streptomycin (STR) and doxycycline (O) on Staphylococcus.

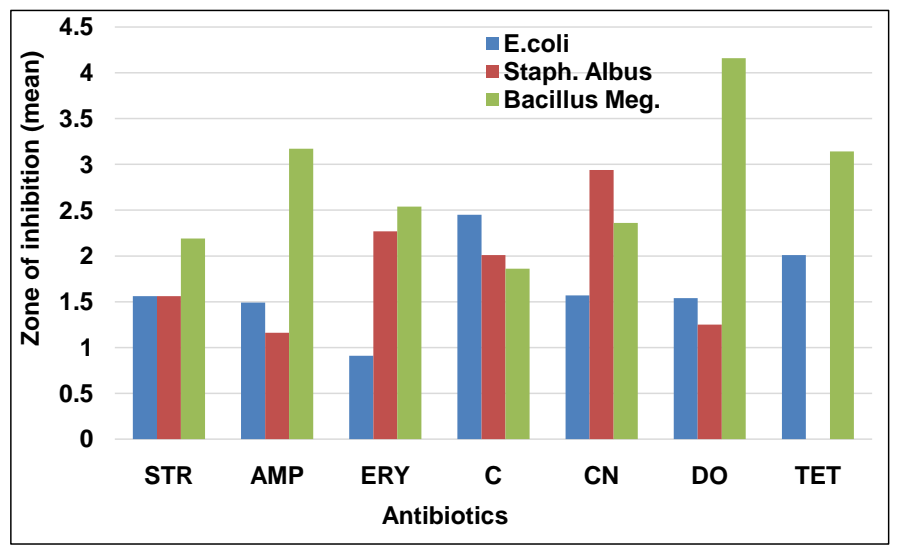

Figure 4. Comparison of different antibiotics on bacteria strains. Relationship between antibiotics: ampicillin (AMP), tetracycline (TET), erythromycin (ERY), chloramphenicol (C) cephalexin (CN), streptomycin (STR) and doxycycline (O) and bacteria strains: Staphylococcus, E. coli and Bacillus megaterium.

have more effects on Bacillus meg. Cephalexin and Tetracycline also play significant effects on E. coli. The most effective antibiotic depends on the bacteria, but chloramphenicol proof to have a relatively large zone of inhibition on all three bacteria investigated in this trial. The most effective antibiotic for $E$. coli in this investigation appears to be chloramphenicol, while the least effective is erythromycin. For Staphylococcus albus, the most effective antibiotic is cephalexin, while the least effective is ampicillin. The most effective antibiotic for Bacillus meg is doxycycline while the least effective is chloramphenicol despite its effectiveness in most strains.

A remarkable less significant difference was observed in the resistance pattern of staphylococcus to cephalexin and erythromycin. This reveals that data isolates of staphylococcus epidermidis was resistant to cephalexin and erythromycin. However, the result obtained in the primary data did not indicate significant difference in the treatment. The outcome of this result was supported by the secondary data. The authors did not find significant difference between primary and secondary data. Evidence from primary and secondary data could not find 
any significant difference on the effectiveness of doxycycline on staphylococcus and E. coli, which is a clear indication that this investigation result is supported by the secondary data (Figure 5). On the effectiveness of the antibiotics, doxycycline seems to be effective in the treatment of $E$. coli as both data revealed high zone of inhibition. Cephalexin seems to be more effective in staphylococcus treatment.

Ampicillin did not show promising results on effective treatment of E. coli. However, ampicillin is a beta-lactam antibiotic that attacks Gram-positive and some Gram-negative bacteria (Lawrence and Anthony, 2013) [43]. The amino group in ampicillin allows it to penetrate the outer membrane of Gram-negative bacteria. It will then become an inhibitor of transpeptidase, which is needed for bacterial cell wall formation, and eventually leads to cell disintegration (Anderson and Hughes, 2014) [40]. With the appearance of antibiotic-resistant bacteria, increasing numbers of infections are causing huge losses to both economic concerns and social resources over recent decades, and this has become a global problem (Zhou and Wang, 2013) [14]. Global antibiotic resistance shows no signs of decline, though it may perhaps shift direction (Aslam, 2018) [2].

Many findings suggest that inadequate selection and abuse of antimicrobials may lead to resistance in various bacteria and make the treatment of infections more unlikely (Kolár et al., 2001 [44] and Rasheed et al., 2014 [45]). This investigation reveals that understanding the mechanism in which bacteria evolve to antibiotics will provide valuable machinery that will help develop a more efficient and rapid transfer of antibiotic resistant bacteria.

A research team led by a distinguished Professor of microbiology and molecular genetics of plant, soil and microbial sciences, James Tiedje of Michigan State University state very clearly that, in the fight against the rise of antibiotic resistance bacteria, researchers need to understand the use of antibiotic more efficiently. The team stress that tracking the source of antibiotic resistance is quite complicated because of antibiotic use, which increases the occurrence of widespread resistance (MSU, 2016) [46].

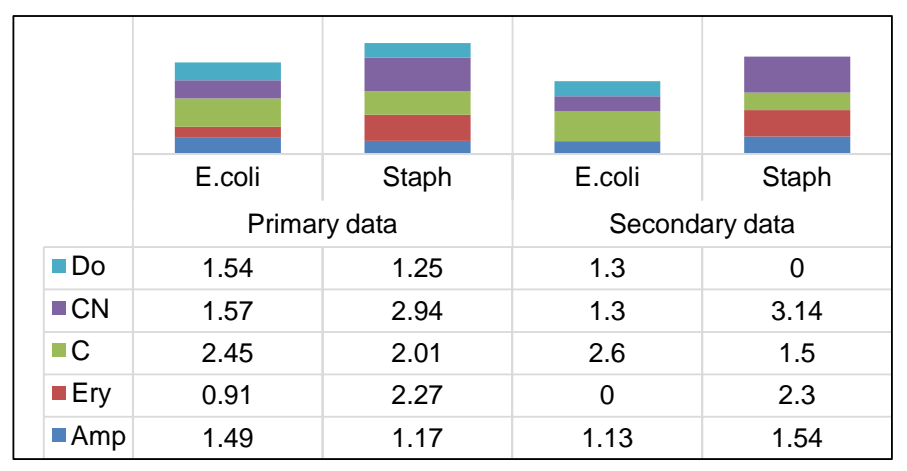

Figure 5. Comparison of primary data and secondary data on E. coli and Staphylococcus using antibiotics: ampicillin (AMP), erythromycin (ERY), chloramphenicol $(\mathrm{C})$ cephalexin $(\mathrm{CN})$ and doxycycline $(\mathrm{O})$. Secondary data source: Sani R. A., Garba S. A. and Oyewole O. A. (2012) [42]. 
Standard deviation was used in this study to test the accuracy of the result in order to ascertain the correlation between them. The data detailed in Figure 6 shows significant different between the results and the mean average. A clear indication of minimal error is represented with smaller values. The higher values indicate high significant difference between the values used to produce the mean.

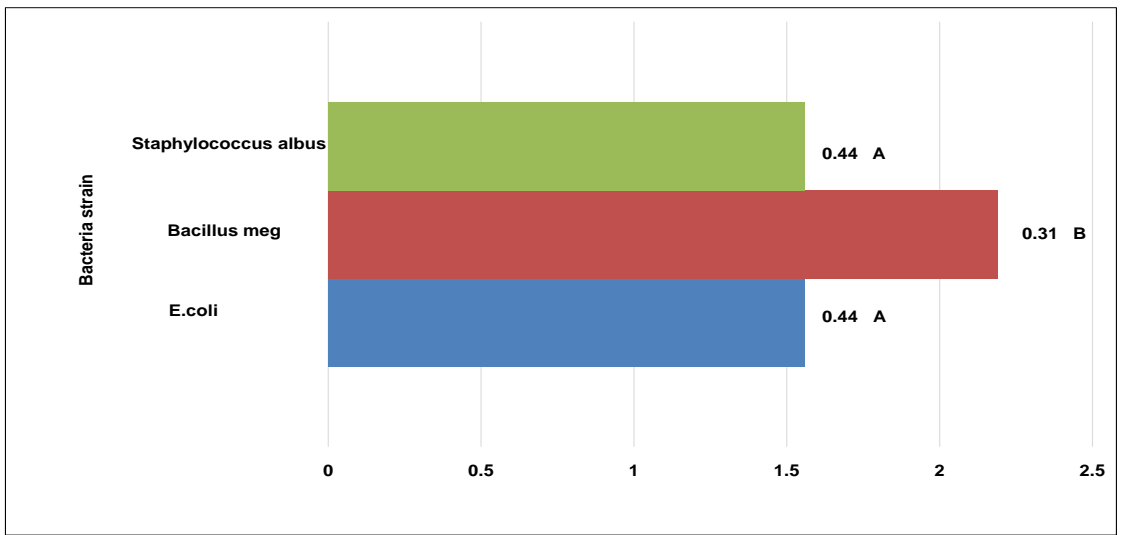

Evaluation of the effectiveness of streptomycin use on bacteria. Data followed by Unequal Letters Significantly Different ( $\mathrm{p} \leq 0.05$; researcher's $\mathrm{t}$-test, $\mathrm{s}^{2}=0.40$ ).

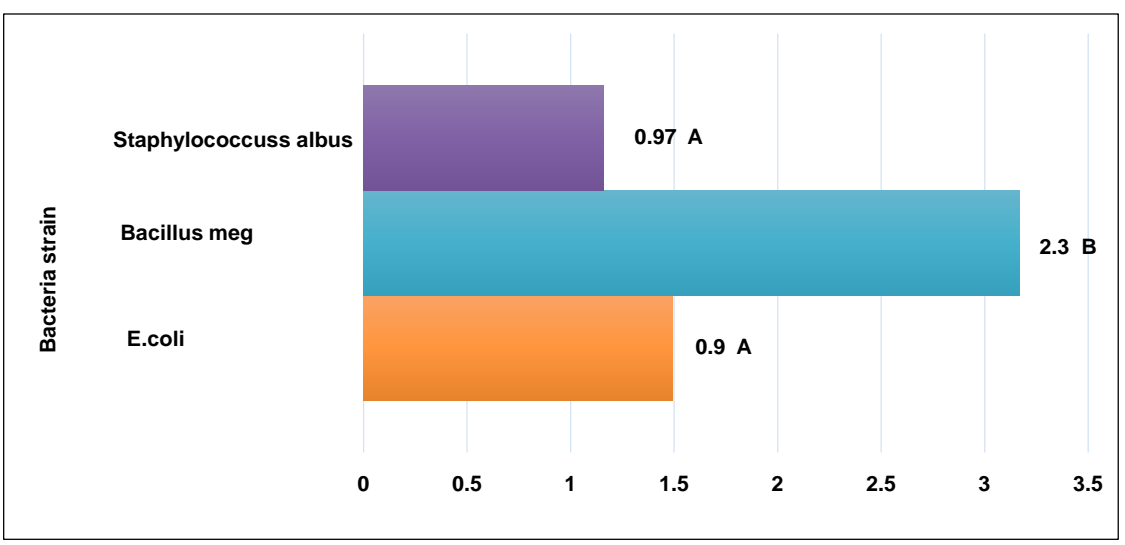

Evaluation of the effectiveness of ampicillin use on bacteria. Data followed by Unequal Letters Significantly Different ( $\mathrm{p} \leq 0.05$; researcher's t-test, $\mathrm{s}^{2}=1.4$ ).

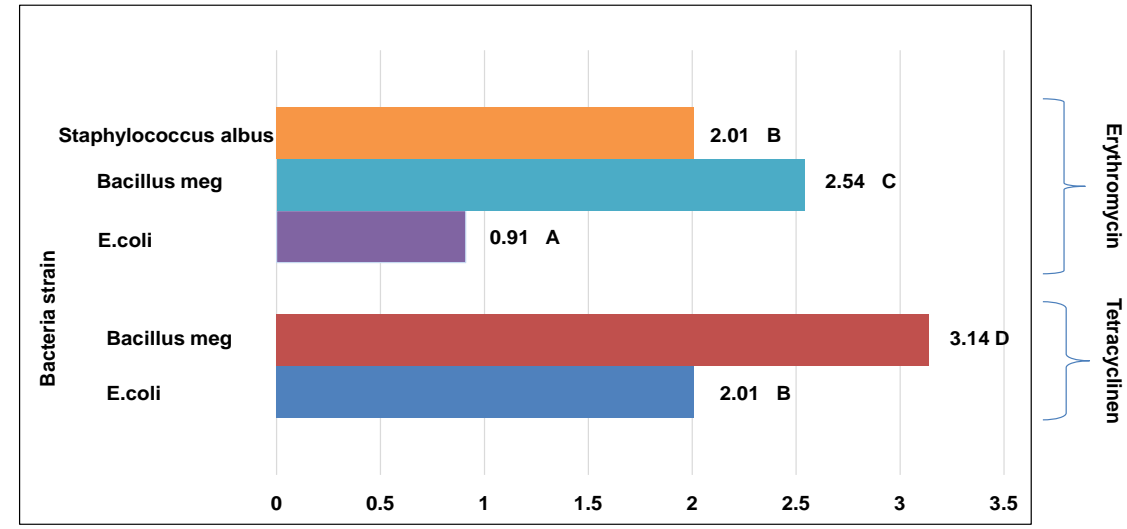

Evaluation of the effectiveness of tetracycline use on bacteria. Data followed by Unequal Letters Significantly Different ( $\mathrm{p} \leq 0.05$; researcher's t-test, $\mathrm{s}^{2}=2.1$ ). 


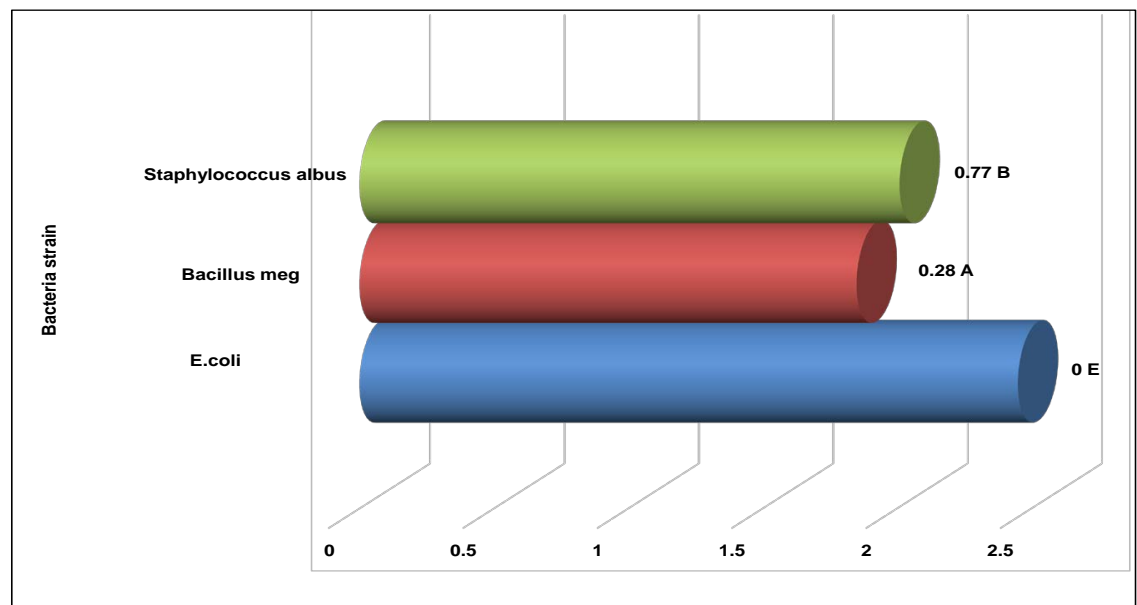

Evaluation of the effectiveness of chloramphenicol use on bacteria. Data followed by Unequal Letters Significantly Different ( $\mathrm{p} \leq 0.05$; researcher's t-test, $\mathrm{s}^{2}=0.35$ ).

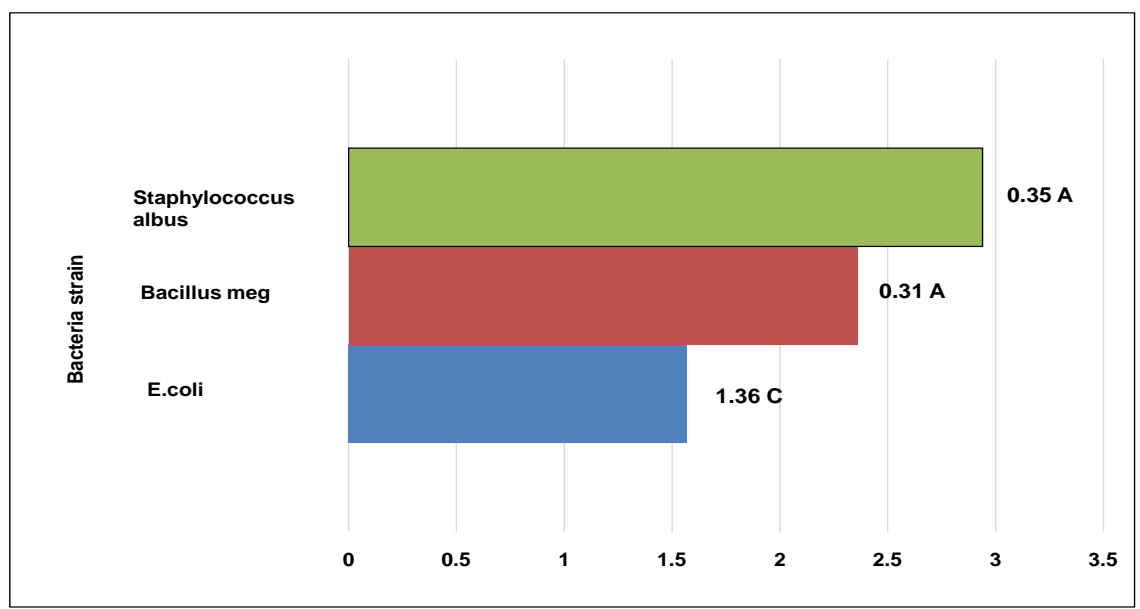

Evaluation of the effectiveness of cephalexin use on bacteria. Data followed by Unequal Letters Significantly Different $\left(\mathrm{p} \leq 0.05\right.$; researcher's t-test, $\left.\mathrm{s}^{2}=0.67\right)$.

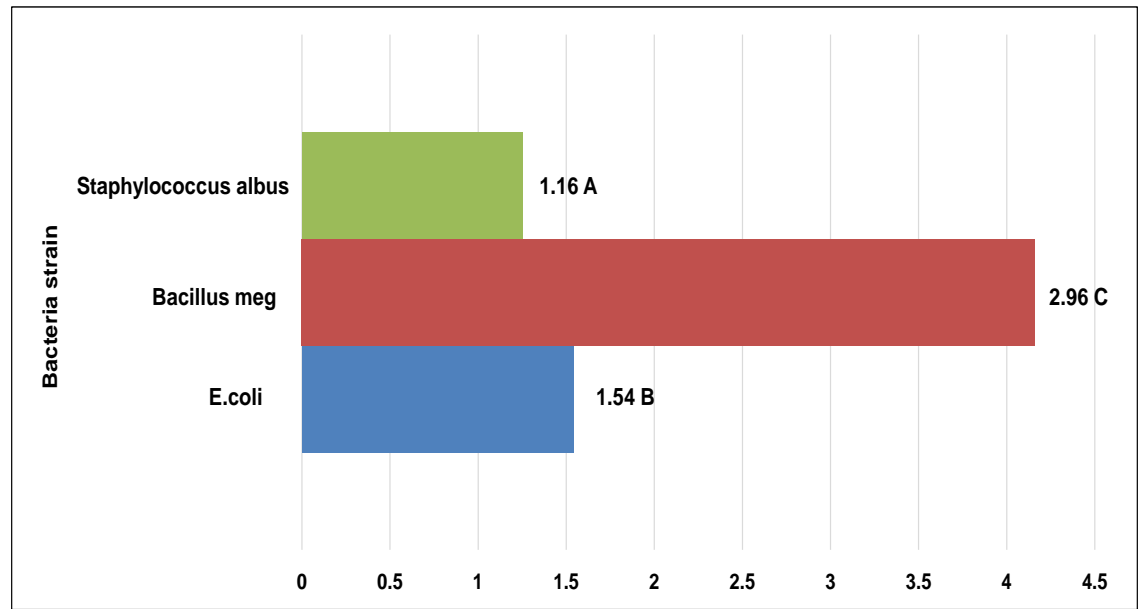

Evaluation of the effectiveness of doxycyclin use on bacteria. Data followed by Unequal Letters Significantly Different ( $\mathrm{p} \leq 0.05$; researcher's t-test, $\mathrm{s}^{2}=1.9$ ).

Figure 6. A test for significant difference of the various treatments. 
Those with zero mean shows that all data values were equal to the mean. Taking example from the use of streptomycin to treat the three bacteria strains, significant difference was not found between Staphylococcus and E. coli. The standard deviation of both was 0.44 each from the mean. However, on the effectiveness of treatment, streptomycin was more effective in the treatment of Bacillus megaterium.

\section{Conclusions}

Antibiotic resistance poses serious threat to human and animal health globally if not used correctly (Berendonk et al., 2015 [13] and Misra et al., 2017 [47]). Important measures are required to reduce the risks posed by antibiotic resistance genes that occur in the environment. Evidence of this trial confides that further research is encouraged to investigate the key contributing factors to antibiotic resistance.

Understanding the influence of antibiotics on multidrug-resistant bacteria is critical to the proper selection and prudent use of antibiotics, while minimising potential collateral consequences (Science Daily, 2017) [48]. The world is currently at alert of the challenge of simultaneous expanding appropriate access to antimicrobials, while restricting inappropriate access, particularly to expensive, newer generation antimicrobials (Laxminaravan et al., 2016) [49].

The outcome of this investigation revealed that further experiments with bacterial strains will provide deeper understanding of bacterial resistance. This study found that antibiotics play significant role in restricting the further invasion of microbes in the body despite some strains being resistance to their treatments. The trial findings suggest that bacterial resistance has been widespread infections that require an immediate attention to prevent it from becoming serious menace in all parts of the world. Early treatment-antibacterial therapy is indeed necessary and should be promptly initiated. However, inadequate use of antibacterial (e.g., doses that are too low, therapy ended prematurely) is a major factor for the selection of resistant strains (Sani R. A., Garba S. A. and Oyewole O. A., 2012) [42]. In a view to tackling the growing problem of antibiotics resistance, a global action plan was endorsed at the World Health Assembly in May 2015 (WHO, 2015) [50]. One of the plan's 5 objectives is to improve awareness and understanding of antibiotic resistance through effective communication, education and training. Antibiotic treatment is one of the main approaches of modern medicine which is used to tackle infections. The "golden era" of antibiotics ranged from the 1930s to 1960s that gave rise to many antibiotics (Aslam, 2018) [2].

There is evidence that numerous attempts have been made to delineate the diverse aspects of antibiotic resistance and researches are still ongoing to with the aim to producing new drugs, however, a principally coordinated campaign is lacking, particularly at the political level worldwide to support researchers' onus of increasing our knowledge on antimicrobial resistance (AMR) threat on global population.

\section{Conflicts of Interest}

The author declares no conflicts of interest regarding the publication of this paper. 


\section{References}

[1] Axenfeld, T. (1908) The Bacteriology of the Eye (Translated by Macnab, A.). In: Balliere, Tindall, and Cox, Williams and Wilkins, London, 77-107. https://doi.org/10.5962/bhl.title.31749

[2] Aslam, B., Wang, W., Arshad, M.I., Khurshid, M., Musammil, S., Rasool, M.H., Nisar, M.A., Alvi, R.F., Aslam M.A., Qamar, M.U., Salamat, M.K.F. and Baloch, Z. (2018) Antibiotic Resistance: A Rundown of a Global Crisis. Infection and Drug Resistance, 11, 1645-1658. https://doi.org/10.2147/IDR.S173867

[3] Li, J., Xie, S., et al. (2017) Antimicrobial Activity and Resistance: Influencing Factors. Frontiers in Pharmacology, 8, 364. https://doi.org/10.3389/fphar.2017.00364

[4] Suleyman, G. and Zervos M.J. (2016) Safety and Efficacy of Commonly Used Antimicrobial Agents in the Treatment of Enterococcal Infections: A Review. Expert Opinion on Drug Safety, 15, 153-167. https://doi.org/10.1517/14740338.2016.1127349

[5] Nathan, C. and Cars, O. (2014) Antibiotic Resistance-Problems, Progress, and Prospects. The New England Journal of Medicine, 371, 1761-1763.

https://doi.org/10.1056/NEJMp1408040

[6] Rosi-Marshall, E.J. and Kelly, J.J. (2015) Antibiotic Stewardship Should Consider Environmental Fate of Antibiotics. Environmental Science \& Technology, 49, 5257-5258. https://doi.org/10.1021/acs.est.5b01519

[7] Catteau, L., Zhu, L., Van Bambeke, F. and Quetin-Leclercq, J. (2018) Natural and Hemi-Synthetic Pentacyclic Triterpenes as Antimicrobials and Resistance Modifying Agents against Staphylococcus aureus. A Review. Phytochemistry Reviews, 1-35. https://doi.org/10.1007/s11101-018-9564-2

[8] Kumara, M., Jaiswal, S., Sodhia, K.S., Shreea, P., Singha, D.K., Agrawal, P.K. and Shukla, P. (2019) Antibiotics Bioremediation: Perspectives on Its Ecotoxicity and Resistance. Environment International, 124, 448-461.

https://doi.org/10.1016/j.envint.2018.12.065

[9] Nielsen, K.M., Gjøen, T., Asare, N.Y.O., Lunestad, B.T., Ytrehus, B., Yazdankhah, S.P. and Tronsmo, A. (2018) Antimicrobial Resistance in Wildlife Potential for Dissemination. Opinion of the Panel on Microbial Ecology of the Norwegian Scientific Committee for Food and Environment. VKM Report.

[10] Davies, J. and Davies, D. (2010) Origins and Evolution of Antibiotic Resistance. Microbiology and Molecular Biology Reviews, 74, 417-433.

https://doi.org/10.1128/MMBR.00016-10

[11] Grenni, P., Ancona, V. and Caracciolo, A.B. (2018) Ecological Effects of Antibiotics on Natural Ecosystems: A Review. Microchemical Journal, 136, 25-39. https://doi.org/10.1016/j.microc.2017.02.006

[12] Rizzo, L., Manaia, C., Merlin, C., Schwartz, T., Dagot, C., Ploy, M.C., Michael, I. and FattaKassinos, D. (2013) Urban Wastewater Treatment Plants as Hotspots for Antibiotic Resistant Bacteria and Genes Spread into the Environment: A Review. Science of the Total Environment, 447, 345-360.

https://doi.org/10.1016/j.scitotenv.2013.01.032

[13] Berendonk, T.U., Manaia, C.M., Merlin, C., Fatta-Kassinos, D., Cytryn, E., Walsh, F., Bürgmann, H., Sørum, H., Norström, M., Pons, M.N., Kreuzinger, N., Huovinen, P., Stefani, S., Schwartz, T. and Kisand (2015) Tackling Antibiotic Resistance: The Environmental Framework. Nature Reviews Microbiology, 13, 310-317.

https://doi.org/10.1038/nrmicro3439 
[14] Zhou, F. and Wang, Y. (2013) Characteristics of Antibiotic Resistance of Airborne Staphylococcus Isolated from Metro Stations. International Journal of Environmental Research and Public Health, 10, 2412-2426. https://doi.org/10.3390/ijerph10062412

[15] Seiler, C. and Berendonk, T. (2012) Heavy Metal Driven Co-Selection of Antibiotic Resistance in Soil and Water Bodies Impacted by Agriculture and Aquaculture. Frontiers in Microbiology, 3, 399. https://doi.org/10.3389/fmicb.2012.00399

[16] Hahn, F. (1967) Chloramphenicol. In: Antibiotics, Springer, Berlin, 308-330. https://link.springer.com/chapter/10.1007/978-3-662-38439-8_22

[17] Brock, T.D. (1961) Chloramphenicol. Bacteriological Reviews, 25, 32. https://doi.org/10.1128/MMBR.25.1.32-48.1961

[18] Davis, B.D. and Feingold, D.S. (1962) Antimicrobial Agents: Mechanism of Action and Use in Metabolic Studies. In: Gunsalus, I.C. and Stanier, R.Y., The Bacteria, Vol. 4, Academic Press, Cambridge, 343-397.

[19] Gale, E.F. (1963) Mechanism of Antibiotic Action. Pharmacological Reviews, 15, 481.

[20] Hahn, F.E. (1964) Actions of Antibiotics on Protein Synthesis. Proceedings of III International Congress of Chemotherapy, Stuttgart, 22-27 July 1963, 215.

[21] Goldberg, I.H. (1965) Mode of Action of Antibiotics. H. Drugs Affecting Nucleic Acid and Protein Synthesis. The American Journal of Medicine, 39, 722. https://doi.org/10.1016/0002-9343(65)90094-X

[22] Vazquez, D. (1966) Mode of Action of Chloramphenicol and Related Antibiotics. 16 th symposium of the Society for General Microbiology, London, April 1966, 169.

[23] Nie, M., Yang, Y., Zhang, Z., Wang, X., Li, H. and Dong, W. (2014) Degradation of Chloramphenicol by Thermally Activated Persulfate in Aqueous Solution. Chemical Engineering Journal, 246, 373-382. https://doi.org/10.1016/j.cej.2014.02.047

[24] Pilehvar, S., Mehta, J., Dardenne, F., Robbens, J., Blust, R. and De Wael, K. (2012) Aptasensing of Chloramphenicol in the Presence of Its Analogues: Reaching the Maximum Residue Limit. Analytical Chemistry, 84, 6753-6758.

https://doi.org/10.1021/ac3012522

[25] Liang, B., Cheng, H.Y., Kong, D.Y., Gao, S.H., Sun, F., Cui, D., Kong, F.Y., Zhou, A.J., Liu, W.Z., Ren, N.Q., Wu, W.M., Wang, A.J. and Lee, D.J. (2013) Accelerated Reduction of Chlorinated Nitroaromatic Antibiotic Chloramphenicol by Biocathode. Environmental Science \& Technology, 47, 5353-5361.

https://doi.org/10.1021/es400933h

[26] Yan, W.F., Xiao, Y., Yan, W.D., Ding, R., Wang, S.H. and Zhao, F. (2019) The Effect of Bioelectrochemical Systems on Antibiotics Removal and Antibiotic Resistance Genes: A Review. Chemical Engineering Journal, 358, 1421-1437. https://doi.org/10.1016/j.cej.2018.10.128

[27] Guo, N., Wang, Y.K., Yan, L., Wang, X.H., Wang, M.Y., Xu, H. and Wang, S.G. (2017) Effect of Bio-Electrochemical System on the Fate and Proliferation of Chloramphenicol Resistance Genes during the Treatment of Chloramphenicol Wastewater. Water Research, 117, 95-101. https://doi.org/10.1016/j.watres.2017.03.058

[28] Sun, F., Liu, H., Liang, B., Song, R.T., Yan, Q. and Wang, A.J. (2013) Reductive Degradation of Chloramphenicol Using Bioelectrochemical System (BES): A Comparative Study of Abiotic Cathode and Biocathode. Bioresource Technology, 143, 699-702. https://doi.org/10.1016/j.biortech.2013.06.084

[29] Yan, W.F., Guo, Y.Y., Xiao, Y., Wang, S.H., Ding, R., Jiang, J.Q., Gang, H.Y., Wang, H., Yang, J. and Zhao, F. (2018) The Changes of Bacterial Communities and Antibiotic Resistance Genes in Microbial Fuel Cells during Long-Term Oxytetracycline 
Processing. Water Research, 142, 105-114.

https://doi.org/10.1016/j.watres.2018.05.047

[30] Wang, A.J., Cheng, H.Y., Liang, B., Ren, N.Q., Cui, D., Lin, N., Kim, B.H. and Rabaey, K. (2011) Efficient Reduction of Nitrobenzene to Aniline with a Biocatalyzed Cathode. Environmental Science \& Technology, 45, 10186-10193.

https://doi.org/10.1021/es202356w

[31] Potrykus, J. and Wegrzyn, G. (2011) Chloramphenicol-Sensitive Escherichia coli Strain Expressing the Chloramphenicol Acetyltransferase (cat) Gene. The American Society of Microbiology, Washington DC. https://doi.org/10.1128/AAC.45.12.3610-3612.2001

[32] Lacks, S. and Gros, F. (1960) A Metabolic Study of the RNA-Amino Acid Complex in Escherichia coli. Journal of Molecular Biology, 1, 301. https://doi.org/10.1016/S0022-2836(59)80012-7

[33] Franklin, T.J. and Godfrey, A. (1965) Resistance of Escherichia coli to Tetracyclines. Biochemical Journal, 94, 54-60. https://doi.org/10.1042/bj0940054

[34] Grossman, T.H. (2019) Tetracycline Antibiotics and Resistance. Cold Spring Harbor Laboratory Press, Cold Spring Harbor, Tetraphase Pharmaceuticals, Watertown. http://perspectivesinmedicine.cshlp.org/content/6/4/a025387.full.pdf https://doi.org/10.1101/cshperspect.a025387

[35] Dürckheimer, W. (1975) Tetracyclines: Chemistry, Biochemistry, and Structure-Activity Relations. Angewandte Chemie International Edition, 14, 161-167. https://doi.org/10.1002/anie.197507211

[36] Chopra, I. and Robert, M. (2001) Tetracycline Antibiotics: Mode of Action, Applications, Molecular Biology, and Epidemiology of Bacterial Resistance. Microbiology and Molecular Biology Reviews, 65, 232-260. https://doi.org/10.1128/MMBR.65.2.232-260.2001

[37] Sliman, R., Rehm, S. and Shlaes, D.M. (1987) Serious Infections Caused by Bacillus Species. Medicine (Baltimore), 66, 218-223. https://doi.org/10.1097/00005792-198705000-00005

[38] Aslim, B., Saglam, N. and Beyatli, Y. (2002) Determination of Some Properties of Bacillus Isolated from Soil. Turkish Journal of Biology, 26, 41-48.

[39] Lee, H.H., Molla, M.N., Cantor, C.R. and Collins, J.J. (2010) Bacterial Charity Work Leads to Population-Wide Resistance. Nature, 467, 82-85. https://doi.org/10.1038/nature09354

[40] Andersson, D.I. and Hughes, D. (2014) Microbiological Effects of Sublethal Levels of Antibiotics. Nature Reviews Microbiology, 12, 465-478. https://doi.org/10.1038/nrmicro3270

[41] Rayner, C. and Munckhof, W.J. (2006) Antibiotics Currently Used in the Treatment of Infections Caused by Staphylococcus aureus. Internal Medicine Journal, 36, 142-143. https://doi.org/10.1111/j.1444-0903.2005.00976.x

[42] Sani, R.A., Garba, S.A. and Oyewole, O.A. (2012) Antibiotic Resistance Profile of Gram-Negative Bacteria Isolated from Surgical Wounds in Minna, Bida, Kontagora and Suleja Areas of Niger State. American Journal of Medicine and Medical Sciences, 2, 20-24. https://doi.org/10.5923/j.ajmms.20120201.05

[43] Lawrence, K. and Anthony, M. (2013) The Effects of Ampicillin on the Growth of Escherichia coli. North Carolina State University, Department of Microbiology. https://pdfs.semanticscholar.org/dba0/caec7215d0e1283db9dbdde35dc7e546d8db.p df?_ga=2.17167088.877936558.1589294020-1282033662.1589294020 
[44] Kolár, M., Urbánek, K. and Látal, T. (2001) Antibiotic Selective Pressure and Development of Bacterial Resistance. International Journal of Antimicrobial Agents, 17, 357-363. https://doi.org/10.1016/S0924-8579(01)00317-X

[45] Rasheed, M.U., Thajuddin, N., Ahamed, P., Teklemariam, Z. and Jamil, K. (2014) Antimicrobial Drug Resistance in Strains of E. coli Isolated from Food. The Revista do Instituto de Medicina Tropical de São Paulo, 56, 341-346. https://doi.org/10.1590/S0036-46652014000400012

[46] MSU (2016) Antibiotic Resistance Genes Increasing. https://www.sciencedaily.com/releases/2016/04/160412132610.htm

[47] Misra, R., Virmani, R., Dhakan, D. and Maji, A. (2017) Tackling the Antibiotic Resistance: The "Gut" Feeling. In: Drug Resistance in Bacteria, Fungi, Malaria, and Cancer, Springer, Berlin, 325-338. https://doi.org/10.1007/978-3-319-48683-3_14 https://link.springer.com/chapter/10.1007/978-3-319-48683-3_14

[48] Science Daily (2017) Investigating the Collateral Effects of Antibiotics. The American Society for Microbiology, Washington DC. https://www.sciencedaily.com/releases/2017/11/171101141719.htm

[49] Laxminarayan, R., Matsoso, P., Pant, S. and Brower, C. (2016) Access to Effective Antimicrobials: A Worldwide Challenge. Antimicrobial: Access and Sustainable Effectiveness, 387, 168-175. https://doi.org/10.1016/S0140-6736(15)00474-2

[50] WHO (2015) WHO Multi-Country Survey Reveals Widespread Public Misunderstanding about Antibiotic Resistance.

https://www.who.int/news-room/detail/16-11-2015-who-multi-country-survey-reve als-widespread-public-misunderstanding-about-antibiotic-resistance 